\title{
Isolation and Microscopic Investigation of Entomopathogenic Nematodes (EPNs) Occurring in Barak Valley, Assam, India
}

\author{
Rupak Sharma ${ }^{1,2 *}$, Baby Singha ${ }^{1}$, Subhadeep Roy Choudhury ${ }^{2}$ and Gouriduttsharma ${ }^{3}$ \\ ${ }^{1}$ Department of Zoology, G.C College, Silchar, Assam, India \\ ${ }^{2}$ Assam University, Department of Life Science and Bio-informatics, Silchar, Assam, India \\ ${ }^{3}$ BilaspurUniversity, Chattishgarh, India \\ *Corresponding author
}

\section{A B S T R A C T}

\begin{tabular}{|l|}
\hline K e y w o r d s \\
Entomopathogenic \\
nematodes, Crop Field, \\
$\begin{array}{l}\text { Steinernema sp., } \\
\text { morphology, Barak } \\
\text { Valley, Assam }\end{array}$ \\
\hline Article Info \\
\hline $\begin{array}{l}\text { Accepted: } \\
\text { 16 March } 2018 \\
\text { Available Online: } \\
\text { 10 April 2018 }\end{array}$ \\
\hline
\end{tabular}

\section{Introduction}

Entomopathogenic nematodes are obligate lethal parasites of insect pests and thus use as effective bio-control agent in Integrated Pests Management. Due to successful use of these nematodes and non - pathogenic nature to other fauna, several surveys were conducted from decades to isolate the EPNs from different regions all over the world. Entomopathogenic nematodes (EPNs) in the family Steinernematidae (Chitwood and Chitwood) are insect parasites and capable of infecting a broad range of insect species. They have been used as biological control agents of insect pests in a variety of crops (Gaugler and Kaya, 1990; Kaya and Gaugler, 1993). The third stage juvenile is only the infective stage and they are free - living form present in soil. The IJ carry symbiotic bacteria of genus Xenorhabdus Poinar and Thomas. The IJ carries cells of the bacterial symbionts in its intestine. When the IJ finds a susceptible host, it invades and penetrates into the host's haemocoel through natural openings (i.e., anus, mouth, or spiracles). The IJ then releases the symbiotic bacterium that kills the host within $48 \mathrm{hr}$ by septicemia. The bacterium produces antibiotics that prevent other microorganisms from colonizing the cadaver. 
In addition to serving as a food source for the nematode, the bacterium digests the host tissues, thereby providing suitable nutrients for nematode growth and development.

The family Steinernematidae comprises of two genera, Steinernema Travassos 1927 with more than 59 described species and Neosteinernema Nguyen and Smart 1994, with only one species. The most updated biogeographic account indicates that these nematodes have been isolated from all continents (except Antarctica). However, soil surveys conducted in different areas of the world have demonstrated variability in abundance across seasons, habitats, and geographic regions.

\section{Materials and Methods}

\section{Propagation of isolates}

The soil has been collected from different locality of Barak Valley, Assam. Soil samples are collected from different habitat includes vegetable fields, Tea garden, Pineapple garden, and Bamboo bush etc. Relatively shady and moist sites were chosen for sampling. Soil samples were collected at a depth of $10-15 \mathrm{~cm}$ of $27-37^{\circ} \mathrm{C}$. The nematodes were propagated in last in-star larvae of greater wax moth, Galleria mellonella at 28$30{ }^{\circ} \mathrm{C}$ by baiting technique (Bedding and Akhurst, 1975). Emerging IJ was harvested in modified White traps following procedures described by Kaya and Stock (1997).The harvested nematodes are washed with distilled water two to three times. To maximize the recovery of nematodes, fresh $G$. mellonella larvae were used for second baiting round.

\section{Light microscopy}

For light microscopy, both infective juveniles (IJs) as well as adult nematodes are collected from insect cadaver. Adult males and females were collected by dissecting the $5^{\text {th }}$ instar larvae of G. mellonella after 2 DAI (Day After infection) as suggested by Nguyen and Smart (1995). On the other hand infective juveniles were obtained from insect cadaver by using white trap method (White, 1927) from insect cadaver 5 - 6 DAI. For light microscope observations, 20 IJS, 20 adults are examined alive. In order to study more morphological features nematodes were heat killed first at $50^{\circ} \mathrm{C}$ in warm water. The heat killed nematodes were placed in triethanolamine formalin (TAF) fixative (Kaya and Stock, 1997) and processed to glycerine for mounting (Seinhorst, 1959). Type specimens are mounted in using glycerine. Cover glass supports were used to prevent the flattening of nematode specimens. Observations were made from live and mounted specimens using an Olympus CX 31microscope equipped with differential interference contrast optics.

\section{Results and Discussion}

The soil samples were collected from different habitat of Cachar district, Assam. The habitat includes A total of 170 soil samples were collected from different sites of Cachar district of which from only 4 sites the entomopathogenic nematodes were recovered. The percent recovery was $2.6 \%$.the present recovery was very low in comparison with a survey conducted by Hazir et al., (2003) in Turkey. Other recovery includes $3.9 \%$ recovered by Rosa et al., (2002) Northern Ireland and by Rajkumar et al., (2002) in Udaipur with $3.3 \%$ etc. The soil type of positive sites was sandy and loamy with $\mathrm{pH}$ 5.5-5.9 and the temperature was $19^{\circ} \mathrm{C}$ to $23^{\circ} \mathrm{C}$. All the recovery was done during rabbi season from rhizospheric soil of bamboo and from vegetable field. All the isolates from the family Steinernematidae of the genus Steinernema were recovered. Over the past few years the proper diagnosis is incomplete without morphometrics along with molecular 
identification. So without this aspect the work is incomplete and has to overcome in this field of diagnosis in near future.

\section{Family Steinernematidae}

\section{Diagnosis}

Order Rhabditida,

Alloionematoidea, family Steinernematidae, Typegenus: Steinernema Travassos, 1927. Obligate insect parasites of insects. Infective stage carry symbiotic bacteria in the bacterial pouch of the intestine. Both males and females are necessary for reproduction.

\section{Adult female}

Adult females are larger in size in comparison to adult male. Body cuticle smooth. Esophagus with procorpus cylindrical, muscular; meta-corpus swollen; isthmus distinct. Excretory pore is anterior to nerve ring with opposed reflexed ovaries. Vulva with lips at the mid region of the body (Fig. $1)$.

Fig.1 Microscopic pictures of adult female: [a] anterior body part showing excretory pore and oesophageal bulb, [b] vulva, [c] posterior body part with anus, [d] adult female containing IJs inside the body
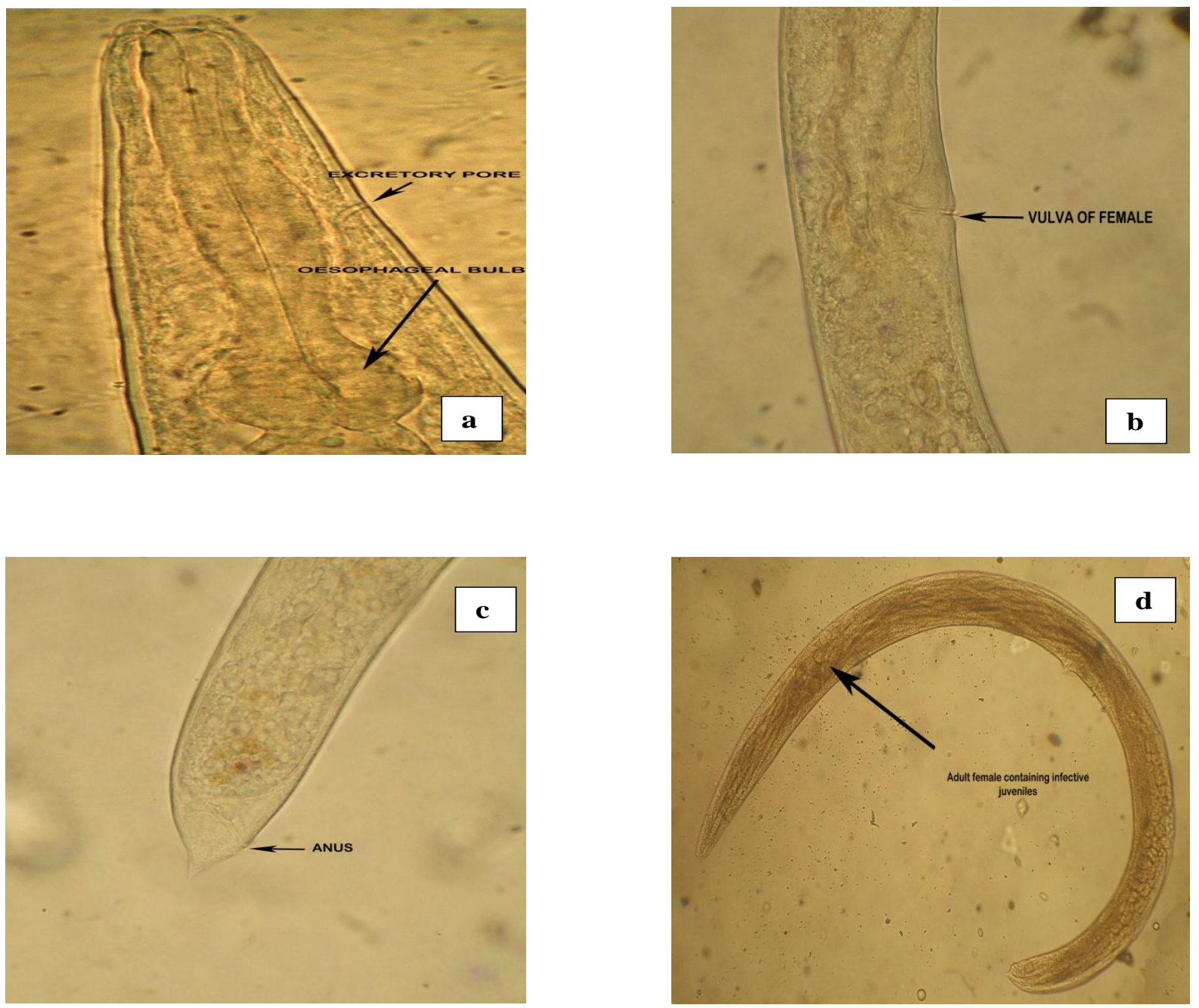
Fig.2 Microscopic pictures of adult male: [a] Posterior part showing spicule and gubernaculum [b] whole body of adult male
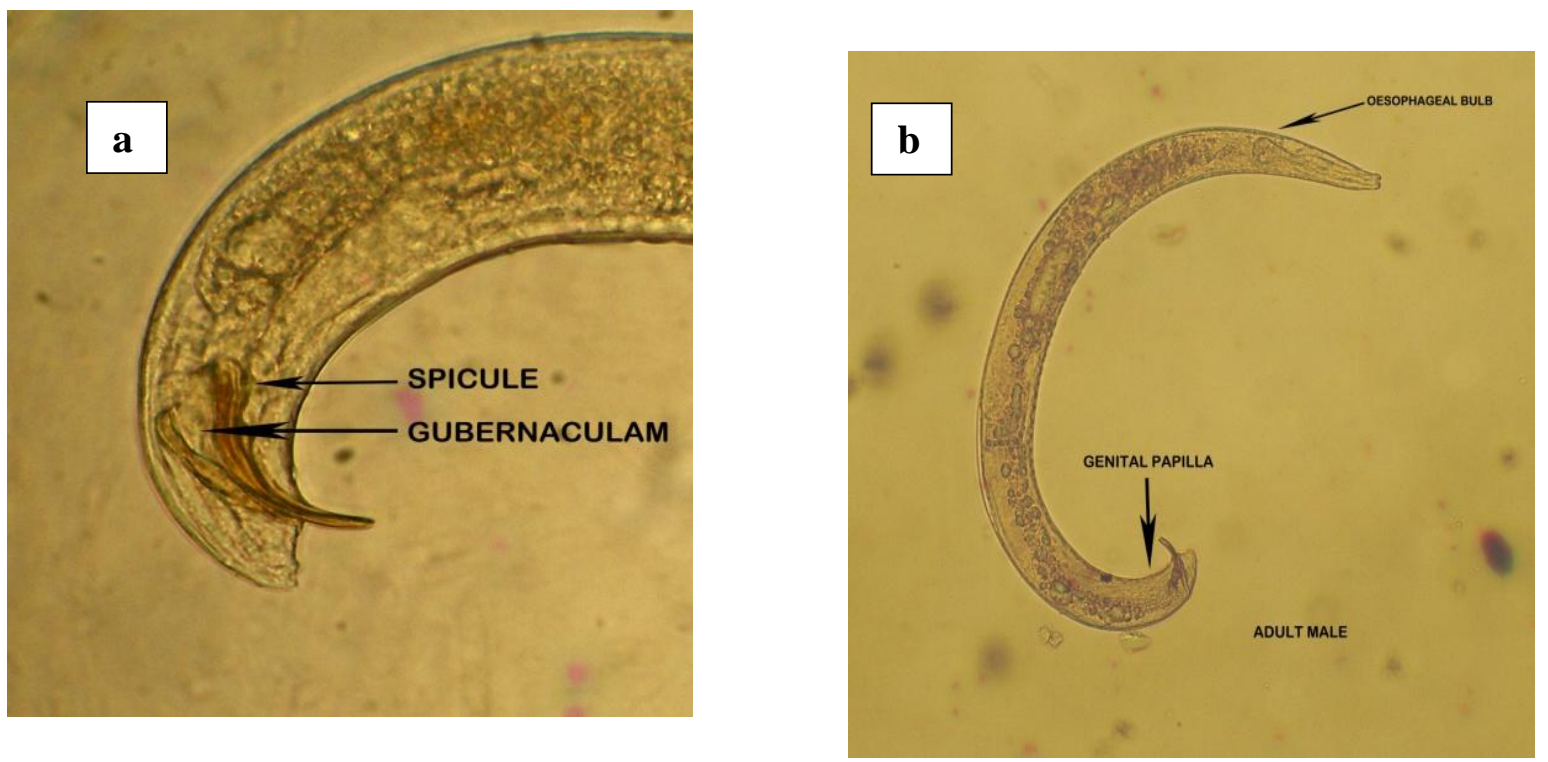

Fig.3 Infective juvenile

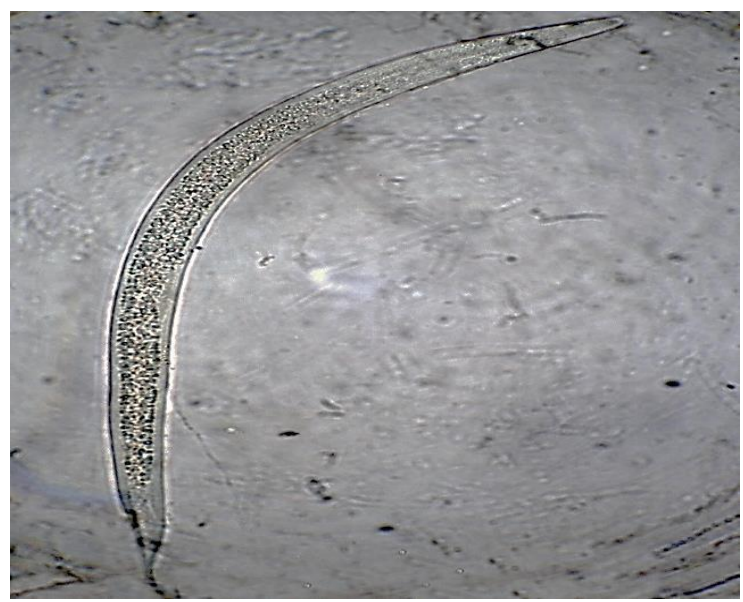

Tail somewhat long with tail mucron. Tail shorter than anal body width. The older adult female were consumed by young infective juveniles and eventually killing the female. Nervering surrounding isthmus, just anterior to basal bulb.

\section{Adult male}

Male is smaller than the female. Posterior region of the body curved ventrally. Spicules paired and separate brown in color and gubernaculum long. Gubernaculam is curved ventrally at the anterior end. Second-generation male similar to that of the first generation except body, spicule and gubernaculum shorter and thinner. Tail mucron is present (Fig. 2).

Excretory pore located mostly anterior to basal bulb. Esophagus with cylindrical procorpus. Head (manubrium) of spicules with rounded anterior end. 


\section{Infective juvenile}

Body is slender with closed mouth and anus. Sheath (second-stage cuticle) present immediately after harvesting, but many IJ will lose their sheath in storage. Labial region smooth, rounded anteriorly, continuous with body. Excretory pore is anterior to the nerve ring. Tail is long and tail attenuate, tapering gradually with constriction on dorsal side (Fig. $3)$.

\section{Acknowledgement}

We thank the Department of Science and technology, Govt. of India for providing funds to carry out the present investigations. We are also thankful to Nematlogy division of Indian Agricultural Reasearch Institute (IARI) for their helping hand during this investigation.

\section{References}

Bedding, R.A. and Akhurst, R.J. (1975). A simple technique for detection of insect parasitic rhabditid nematodes in soil. Nematologica 21, 109-110.

Gaugler, R. and Kaya, H.K. (1990). Entomopathogenic nematodes in biological control. Boca Raton, FL, USA, CRC Press, 365 pp.

Hazir, S., Keskin, N., Stock, S.P., Kaya, H.K and Ozcan, S. (2003). Diversity and distribution of entopmopathogenic nematodes (rhabditida: Steinernematidae and Heterorhabditidae) in Turkey. Biodiversity and conservation 12: $375-$ 386.

Hominick, W.M. (2002). Biogeography. In: Gaugler, R. (Ed.). Entomopathogenic nematology. Wallingford, UK, CABI Publishing, pp. 115-143.
Kaya, H.K. and Stock, S.P. (1997). Techniques in insect nematology. In: Lacey, L.A. (Ed.). Techniques in insect pathology. London, UK, Academic Press, pp. 281324.

Nguyen, K. B. and Smart, J R, G.C. (1995). Morphometrics of infective juveniles of Steinernema spp. and Heterorhabditis bacteriophora (Nemata: Rhabditida). Journal of Nematology 27, 206-212.

Rajkumar, Arunaparihar and Siddiqui, A.U (2002). Isolation of indigenous entomopathogenic nematodes from Udaipur. Indian Journal of Nematology 33: 171-196.

Razia, M. and Sivaramakrishnan, S. Isolation and Identification of Entomopathogenic Nematodes of Kodaikanal Hills of South India.

Seinhorst, J. W. (1959). A rapid method for the transfer of nematodes from $\check{Z}$ fixative to anhydrous glycerin. Nematologica 4, 6 769.

Susurluk, A. (2011). Potential of Steinernemafeltiae (Rhabditida: Steinernematidae) as a biological control agent against the cabbage maggot Delia radicum (Diptera: Anthomyiidae) in oilseed rape. Turk J Agric For 35: 413 419.

Tabassum, K.A., Shahina, F., and Abid, B., 2005. Occurrence of entomopathogenic nematodes in Pakistan, Pak. J. Nematol., 23 (1): 99-102.

White, G. F. (1927). A method for obtaining infective nematode larvae from cultures. Science 66, 302-303.

Woodring, J.L. and Kaya, H.K. 1988. Steinernematid and heterorhabditid nematodes. A handbook of techniques. Southern Cooperative Series Bulletin 331.

\section{How to cite this article:}

Rupak Sharma, Baby Singha, Subhadeep Roy Choudhury and Gouriduttsharma. 2018. Isolation and Microscopic Investigation of Entomopathogenic Nematodes (EPNs) Occurring in Barak Valley, Assam, India. Int.J.Curr.Microbiol.App.Sci. 7(04): 1835-1839.

doi: https://doi.org/10.20546/ijcmas.2018.704.208 